\title{
Prevalence, Intensity and Effects of Anthelminthic Drug Efficacy on Gastrointestinal Helminths in Nkambe, North West Region Cameroon
}

\author{
Bup R Manjuh ${ }^{1}$, Khan P Vincent ${ }^{1}$, Noumedem AC Nadia ${ }^{2}$ and Yamssi Cedric ${ }^{3 *}$ \\ ${ }^{1}$ Department of Animal Biology, Faculty of Science, University of Dschang, Cameroon \\ ${ }^{2}$ Department of Microbiology, Hematology and Immunology, Faculty of Medicine and Pharmaceutical Sciences, University \\ of Dschang, Cameroon
}

${ }^{3}$ Department of Biomedical Sciences, Faculty of Health Sciences, University of Bamenda, Cameroon

*Corresponding author: Yamssi Cedric, Department of Biomedical Sciences, Faculty of Health Sciences, University of Bamenda, PO Box 39 Bambili, Cameroon, Tel: (237)-677413547

\begin{abstract}
Background: Parasitic infections are major health problems worldwide. These parasitic infections are caused by Helminths and Protozoans. High prevalence is mostly in people with low socio-economic status and this is due to lack of hygiene and sanitation. This study aimed at providing systemic data that will be used to determine the prevalence, intensity and the efficacy of anthelminthic drugs (Albendazole $400 \mathrm{mg}$ and Mebendazole $500 \mathrm{mg}$ ) against gastrointestinal helminths among the population of Nkambe.
\end{abstract}

Methods: Qualitative and quantitative analysis were carried out by Floatation and McMaster count techniques respectively, while the Chi Square Test was used to analyse demographic parameters, Kruskal Wallis test was used to determine the intensities at 0.05 significant level.

Results: Four hundred (400) stool samples were collected and fifty-two 52(13\%) of these samples were infected with at least one nematode species. The intestinal nematodes encountered in this study were: Ascaris lumbricoides, Hookworms and Trichiuris trichiura with the respective prevalences and intensities of infection of $(5.5 \%)$ and $671.43 \pm$ $317.27),(3.75 \%$ and $(1000.00 \pm 228.03),(3.75)$ and $(478.57$ $\pm 237.68)$. From our data analysis, the males $(7.25 \%)$ were infected more than the females $(5.75 \%)$. Participants between $2-10$ and $11-20$ years were more infected than adults with $6.75 \%$ and $3.5 \%$ respective. Faecal egg concentration was $44.2 \%$ and these infections were light and moderate. The cure rate for Albendazole (ALB) against $A$. lumbricoides was $100 \%, 66.67 \%$ for Hookworms and $57 \%$ T. trichuira. Mebendazole (MEB) curing rate for Hookworm was $100 \%$,
A. lumbricoides $83.4 \%$ and was unsatisfactory against $T$. trichuira. The ERR for ALB $400 \mathrm{mg}$ was $100 \%$ for A. lumbricoides, $55 \%$ for Hookworms and $44.27 \%$ for $T$. trichuira. (MEB) $500 \mathrm{mg}$ Egg Reduction Rate (ERR) was 100\% for Hookworms, $62.9 \%$ for A. lumbricoides and T. trichuira had $44.4 \%$.

Conclusion: A single dose of ALB $500 \mathrm{mg}$ is recommended for the treatment of $A$. lumbricoides, Hookworms and $T$. trichuira.

\section{Keywords}

Helminths, Albendazole, Mebendazole, Efficacy, Prevalence, Intensity, Nkambe

\section{Abbreviations}

ALB: Albendazole; CR: Cure Rate; EPG: Egg per gram of faeces; ERR: Egg Reduction Rate; MEB: Mebendazole; NTDs: Neglected Tropical Disease; RHB: Regional Hospital Review Board; SPSS: Statistical Package for Social Science; STHs: Soil Transmitted Helminths

\section{Introduction}

Helminthiasis being a global health burden and is attributed as one of the Neglected Tropical Diseases (NTDs) by medical and international community results to ill-health [1]. They are the major health problems in the tropical and subtropical parts of the world where temperature, humidity, lack of hygiene, poverty, sociocultural habits and demographic factors favor their

Citation: Manjuh BR, Vincent KP, Nadia NAC, Cedric Y (2020) Prevalence, Intensity and Effects of Anthelminthic Drug Efficacy on Gastrointestinal Helminths in Nkambe, North West Region Cameroon. Int J Trop Dis 3:038. doi.org/10.23937/2643-461X/1710038

Accepted: November 09, 2020; Published: November 11, 2020

Copyright: (c) 2020 Manjuh BR, et al. This is an open-access article distributed under the terms of the Creative Commons Attribution License, which permits unrestricted use, distribution, and reproduction in any medium, provided the original author and source are credited. 
development [2]. They are responsible for considerable morbidity and in severe cases, cause mortality [3]. Previous studies indicate that the Neglected Tropical Diseases (NTDs) are widespread among the poor in the Sub Saharan Africa (SSA) [4]. These parasites dwell in the gastrointestinal tract in humans and other animals. The World Health Organization (WHO) estimates that over 2 billion individuals suffer from parasitic infections worldwide, resulting to more than 155,000 thousand deaths per year with $97 \%$ of these deaths occurring in the developed parts of the world [5]. Soil-transmitted helminths (STHs) is a group of nematode worms causing human infections through contact with parasite eggs or larvae that thrive in the warm and moist soil of the world's tropical and subtropical countries including Cameroon. Soil Transmitted Helminths are the most occurring with an estimated $50 \%$ of the world's population, the epidemiology of intestinal parasitic infections shows that these parasites are found in every age group and in both sexes. These infections are higher in Children and the elderly than in middle-aged individuals and between immigrants and refugees [6]. Ascaris lumbricoides a cosmopolitan nematode affects over 1.5 billion people, followed by Ankylostoma 1 billion and T. trichiura 800 million people throughout the world [7]. These intestinal infections caused severe intestinal disorder such as dysentery; diarrhoea, mild abdominal pain, vomiting, and lack of appetite and in some cases lead to mental retardation in children and even affect physical growth and development [8]. In Cameroon, a report from the Cameroonian Public Health Secretary of State revealed that 16.1 million inhabitants with more than 10 million suffer from helminthiasis. The prevalence and intensity of these infections fluctuates from one region to the other [9]. Since 2001, STHs endemic countries have been urged during the $54^{\text {th }}$ World Health Organization [10] assembly to implement periodic and regular deworming of at least once or twice every year among school-aged children and other groups at risk of morbidity in order to eliminate morbidity of STHs in children by 2020 through school-based deworming. The Benzimidazole group usually a single oral dose of Albendazole $(400 \mathrm{mg}$ ) or Mebendazole $(500 \mathrm{mg}$ ) is the most widely distributed among the population. Cameroon adopted the strategic plan for the control of schistosomiasis and STHs in 2004, however the nationwide school-based deworming is still in progress [11]. From this report, the prevalence and intensity of gastrointestinal parasites in Cameroon is high and the control programs against these infections among school-aged children is effective in some regions than others, while in other regions, divisions and sub-divisions, prevalence, intensity and the efficacy of anthelminthic drugs against these infections are not really known. Soil-transmitted helminth infections are usually asymptomatic and the manifestations of these infections are not fatal, contra-

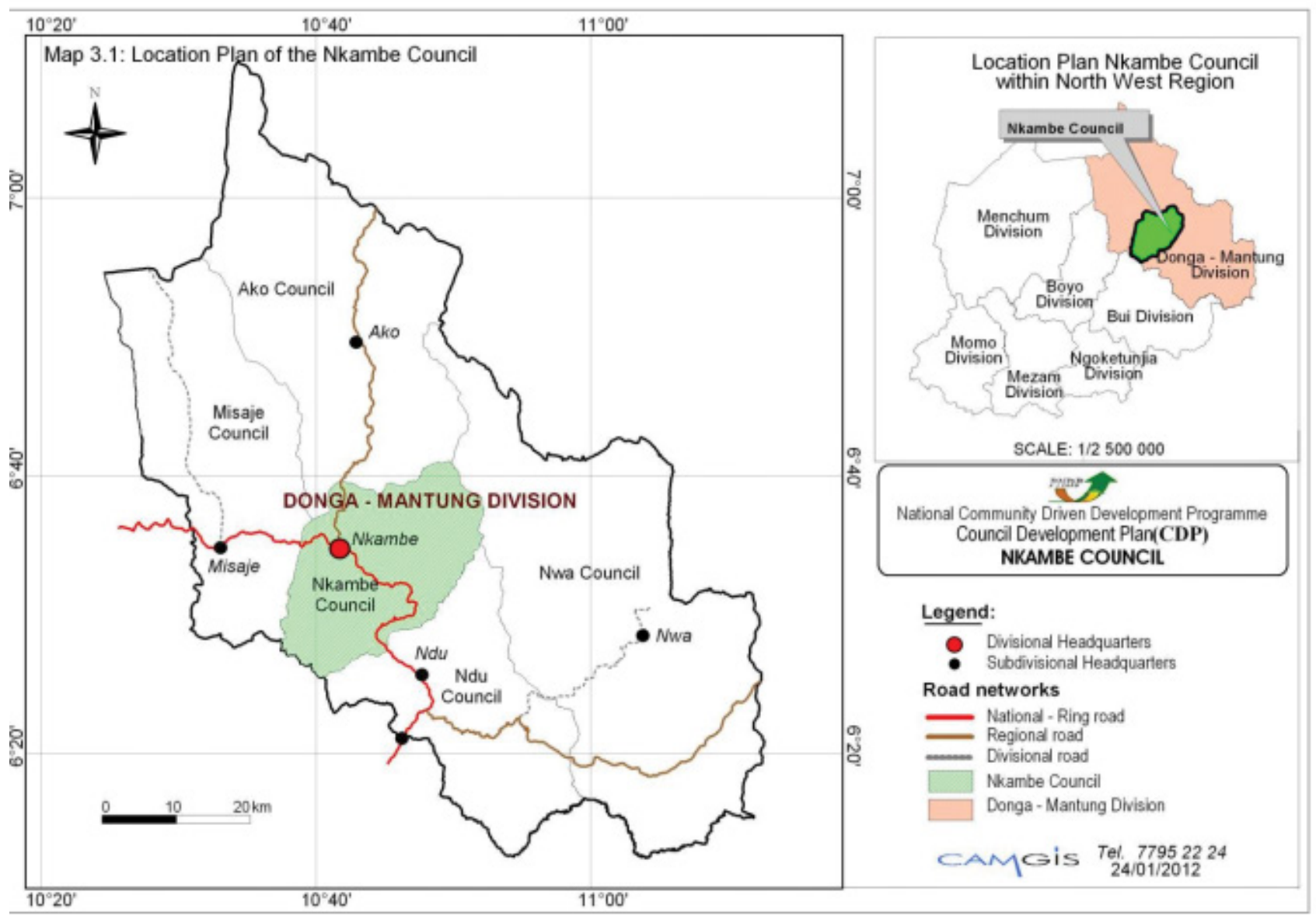

Figure 1: Map of the study area. 
ry to the protozoan's infections which is symptomatic and fatal [6]. This might be the reason why STHs has not received proper attention in research findings and public recognition. Some related effects of STHs is that; they reduced the functioning system of the body, Physical performance is reduced and poor cognitivity in children resulting to a decrease in human financial capital among adults of the infected population [2]. This study aimed at providing systemic data that will be used to determine the prevalence, intensity and the efficacy of anthelminthic drugs (Albendazole $400 \mathrm{mg}$ and Mebendazole $500 \mathrm{mg}$ ) against gastrointestinal helminths among the population of Nkambe.

\section{Material and Methods}

\section{Study area}

Nkambe central sub-division is found in Donga-Mantung Division of the North West Region of Cameroon (Figure 1). It is bordered to the West by Misaje, to the North by Ako, and to the North East by Nwa Sub Division, to the South- East is Ndu Sub Division and to the South- West is Noni Sub Division. It has a surface area of $4874 \mathrm{~km}^{2}$. The geographical coordinates of this municipality is situated between latitude $6^{\circ} 00$ and $6^{\circ} 01.13^{\prime}$ North of the equator and longitudes $10^{\circ} 01.03^{\prime}$ and $10^{\circ}$ $01.45^{\prime}$ East of the Greenwich meridian.

\section{Study population}

Four hundred respondents from three different quarters were selected randomly to be part of this study. The studied population consists of both children and adults with ages ranging from 2-60 years of age and above. Twenty two (22) of these population were in the Nursery school, 228 were in the Primary school, 86 were in the Secondary school, 19 were in the Tertiary institution and 45 individuals had no level of education. The study population was made up of 163 male patients and 237 female patients with the majority being school pupils.

\section{Sample size determination}

A random sampling method was used for the entire population to select quarters. The sample size was calculated using the formula for cross sectional study:

$$
n_{\circ}=z^{2} p q / e^{2}=1.962^{2} \times 0.50 \times 0.50 / 0.05^{2}=384
$$

Where $\mathbf{n}_{\mathbf{0}}=$ is the sample size

$\mathbf{Z}^{2}=$ is the abscissa of the normal curve that cut off an area

$$
\begin{aligned}
& \mathbf{e}^{2}=\text { is the desired level of precision and } \\
& \mathbf{p}=\text { is the estimated proportion. }
\end{aligned}
$$

Therefore the calculated sample size is 384 . The study targeted about 400 sample.

\section{Inclusion criteria}

- $\quad$ All those who were at least two years of age and above were included in the study.

- All those who signed the informed consent form and children whose's parents signed for them and have not taken anthelminthics within the last months prior to the study.

\section{Exclusion criteria}

- $\quad$ All those who were less than two-years-old.

- $\quad$ All those who were on anthelminthic treatment within the previous weeks of the study.

\section{Distribution of information sheet, informed con- sent form and specimen bottles}

A small screw capped plastic bottle with small plastic spoon was provided to each person who fulfilled the above inclusion criteria. They were advised to fill half the bottle with the first faeces first thing the following morning and discard the scoop after use. All the containers were well labeled with the respective sample number, date, quarter and sex. The participants were advised not to mix the faeces with urine so as to avoid contamination. The stool samples were immediately preserved with $10 \%$ aqueous formaldehyde solution [12]. After collection, these stool samples were transported in a dark leak proof bag to Nkambe District Hospital Laboratory for parasitological analysis.

\section{Microscopic examination using the floatation technique}

This simple floatation method (Willis technique) for qualitative analysis was used.

The prevalence $(P)$ was calculated using the formula:

$$
p=\frac{\text { Number of individuals infected }}{\text { Number of individuals examined }} \times 100
$$

\section{Quantitative analysis using the Mc Master Count technique}

For quantitative analysis or determination of the number of eggs per gram (EPG) of faeces, the Mc Master technique described by [13] was used.

The intensity of infection was determined from the parasitic load according to the modified classification as shown in Table 1.

\section{Assessment of drug efficacy}

Assessment of drug efficacy against each STHs based on cure rate and reduction rate in fecal egg count is

Table 1: Classification of nematodes according to intensity of infection [14].

\begin{tabular}{|l|l|l|l|}
\hline Parasites & Light & Moderate & Heavy \\
\hline A. lumbricoides & $50-499$ & $500-999$ & $>1000$ \\
\hline T. trichiura & $50-499$ & $500-999$ & $>1000$ \\
\hline Hookworm & $50-1049$ & $1050-2000$ & $>2000$ \\
\hline
\end{tabular}


based on geometric mean of post intervention of fecal egg count.

Egg count reduction $(\%)=\frac{\text { Initial mean EPG-Final mean EPG }}{\text { Initial mean EPG }}$

\section{Data analysis}

The data collected was analysed using SPSS version 20 software. Chi square test was used to compare between demographic parameters of participant and the prevalence of STHs and the Kruskal Wallis test was used to determine the intensities at 0.05 significant level.

\section{Results and Discussion}

\section{Characteristic of the study population}

On the four hundred participants, three hundred and fifty-five (355) had a level of education. Twenty-two 22 $(5.5 \%)$ of these population were in the Nursery school, 228 (57\%) were in the Primary school, 86 (21.5\%) in the Secondary school, and 19 (4.8\%) in the Tertiary institution. 45 (11.3) individuals had no level of education. The study population was made up of 163 (40.8\%) males' patients and 237 (59.2\%) females patients with majority being children. The three quarters that participated in this study with the number of individuals involved are: Binju 145 (36.3\%), Toh Nkambe 155 (38.2\%) and Moh 100 (25\%). Figure 2, illustrates that females patients were more than males patients with an overall percentage of $59.2 \%$ and $40.8 \%$ respectively.

\section{Distribution of infection in the study population according to age}

The highest number of participants were children

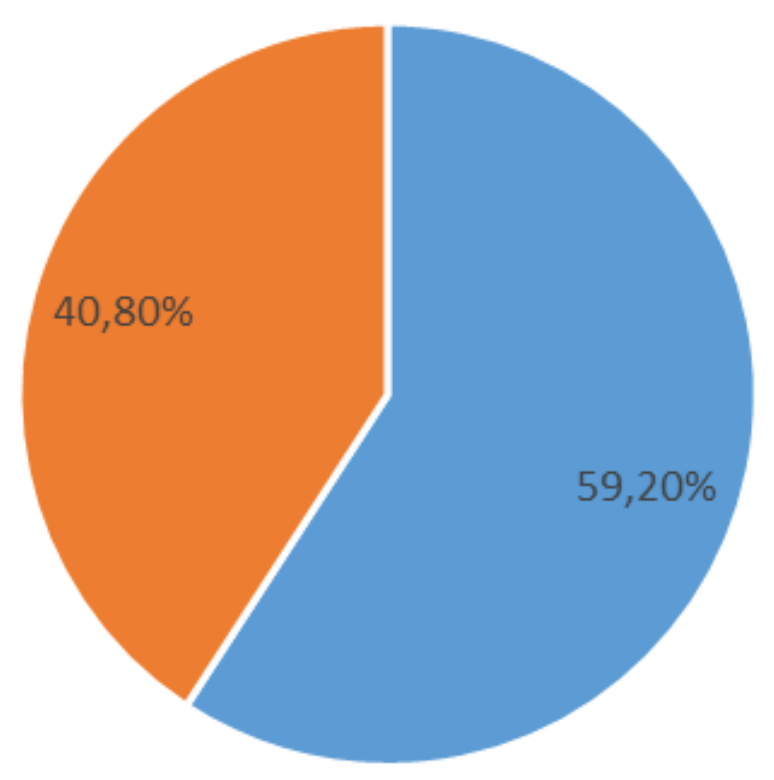

\section{- Females - Males}

Figure 2: Distribution of participant according to age.

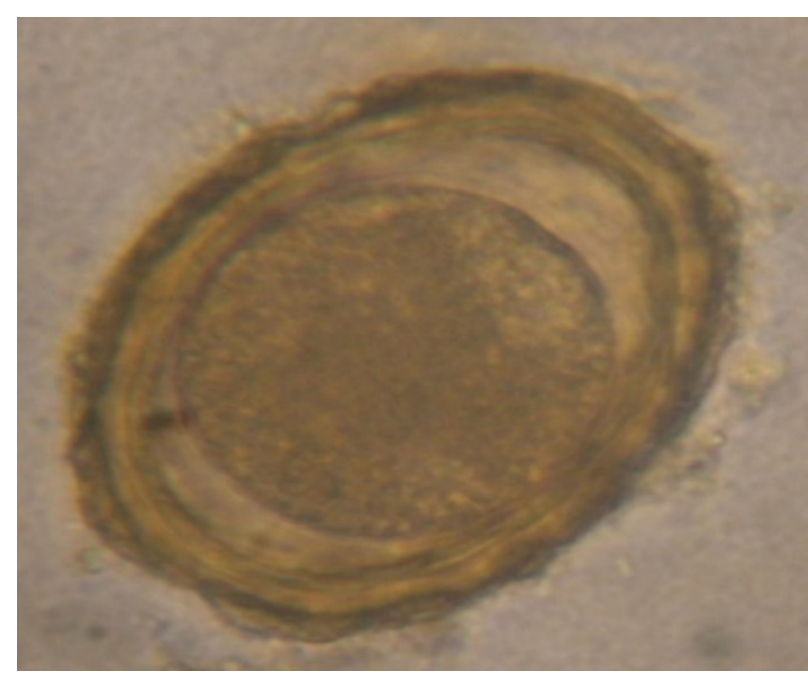

(a)

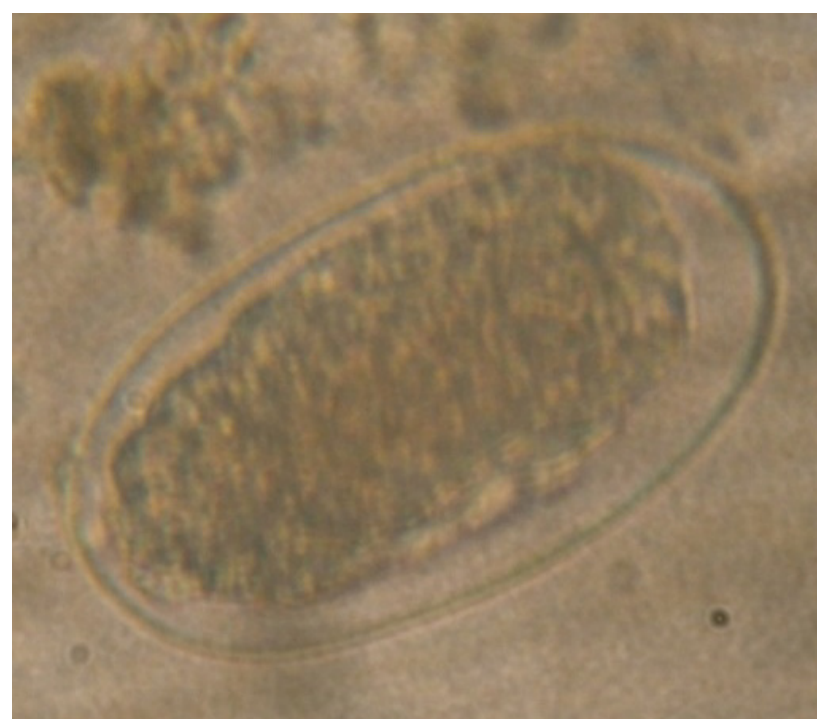

(b)

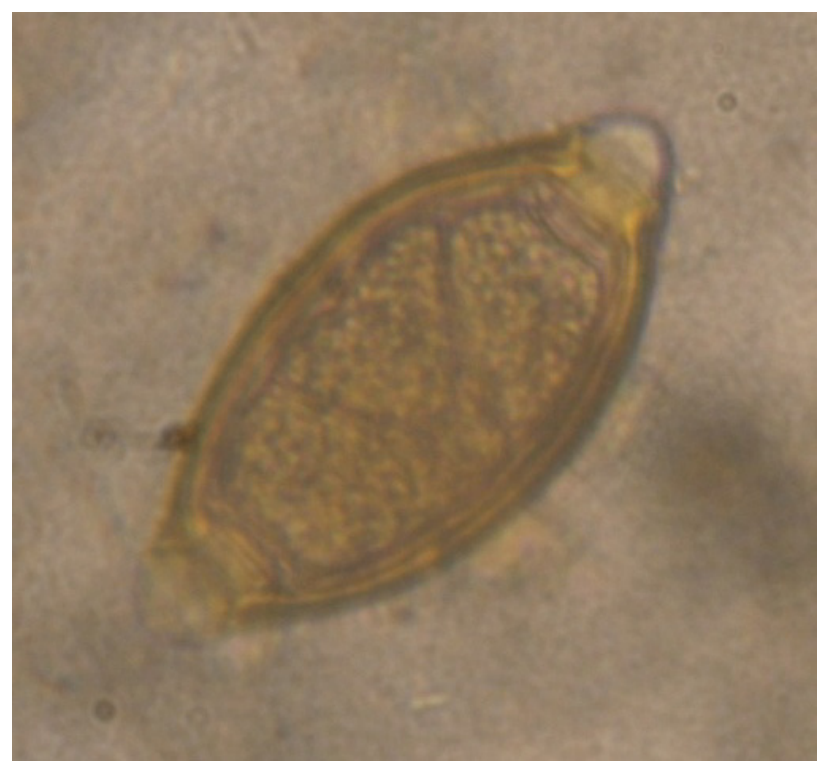

(c)

Figure 3: Images of the three STHs eggs observed during the study at $40 \times$ magnification. (a) Egg of Ascaris lumbricoides; (b) Egg of Hookworm; (c) Egg of Trichuris trichiura. 
between the ages 2-10 years with a percentage of 136 (34\%) followed by those between the ages of 1120 years with $96(24 \%), 21-30$ years 50 (12.5\%), 51-60 years $39(9.8 \%), 31-40$ years $34(8.5 \%)$ and the least distributed age group was those between the ages $>60$ years with $26(6.3 \%)$ representation.

\section{Prevalence of soil transmitted helminthes infec- tions according to demographic factors}

The total number of stool samples examined was 400 , out of this 400 stool samples, 52 respondents were positive with at least one of the STHs species. The different types of helminthes eggs (Figure 3 ) observed during this study and their prevalences are as follows: Ascaris lumbricoides (5.5\%), Hookworms (3.75\%) and Trichuris trichiura $(3.75 \%)$ respectively.

\section{The prevalence of STHs infections according to level of education}

Figure 4 reveals that individuals in each level of education were infected with at least one parasite except those in the University or tertiary institution. Fifty two (52) individuals haboured at least one parasites with total prevalence of $13 \%$. More specifically, $5(1.25 \%)$ from the Nursery, 35 (8.75\%) from the Primary, 10 (2.5\%) from the secondary school, those in the tertiary insti-

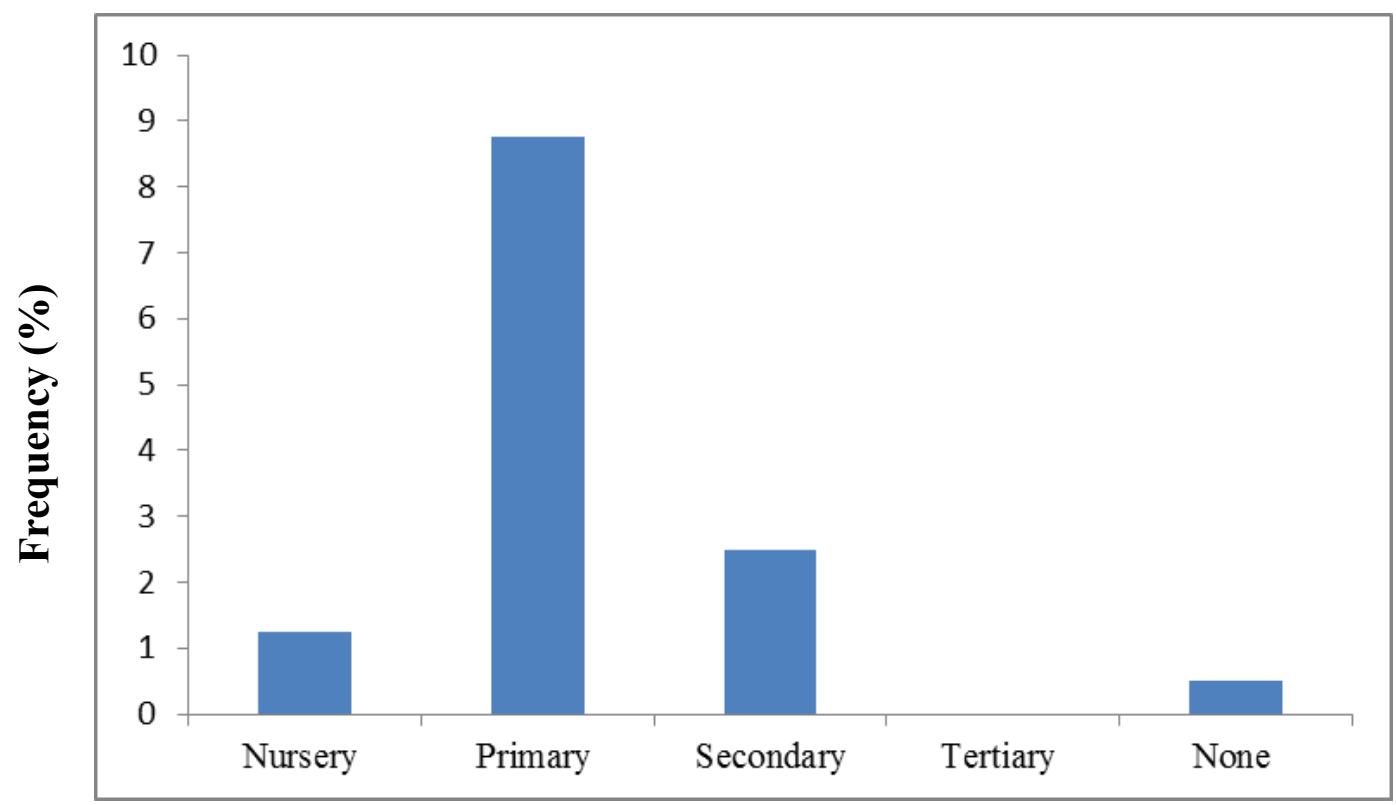

Education

Figure 4: Prevalence of STHs infections according to level of education in Nkambe.

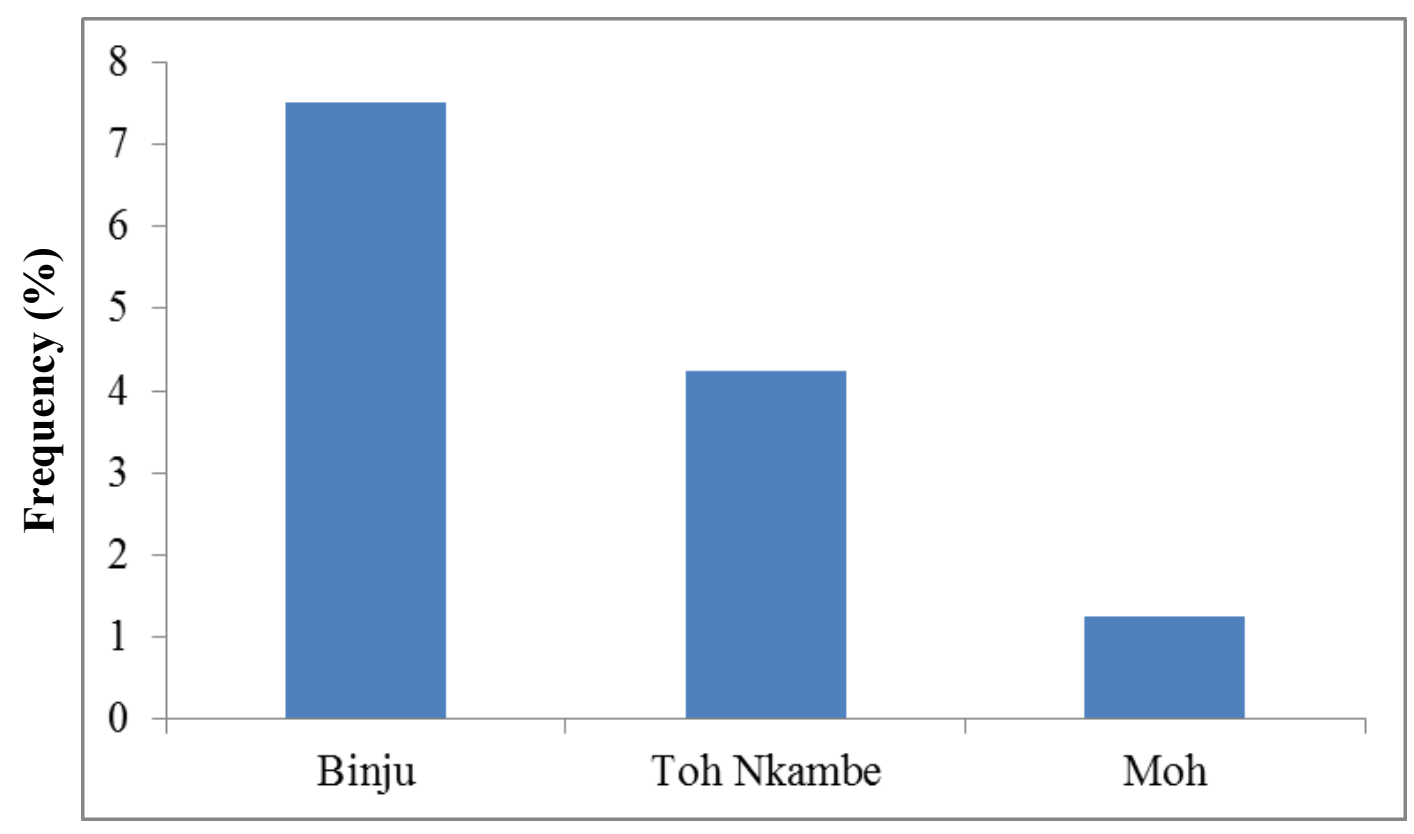

Localities

Figure 5: Prevalence of STHs according to quarters of individuals. 
tution had no infections while those without any level of education had $2(0.5 \%)$ as prevalences. Individuals in the primary sections were the most infected and the least infected were those without any level of education.

\section{Prevalence of STHs according to quarter of partic- ipants}

There are four (4) main quarters in Nkambe which is divided into sub-quarters. Out of these four, three (3) were involved in the study by random sampling method with a total of 400 participants. Binju quarter had the highest prevalence of $20.6 \%$ while Moh had the lowest prevalence of $5 \%$ (Figure 5).

\section{Sex-related prevalence of participants}

In a general manner, both sexes were infected where males were more infected than females. Out of the 163 males examined, 29 (7.25\%) were infected while 23 (5.75\%) females harbored the parasites out of $237 \mathrm{ex}-$ amine.

\section{Prevalence of STHs according to occupation of participant}

The highest number of participants infected were the pupils with a total number of $33(8.25 \%)$, followed by students with a prevalence of $9(2.25 \%)$ while participants with any other job had no infections (Figure 6).

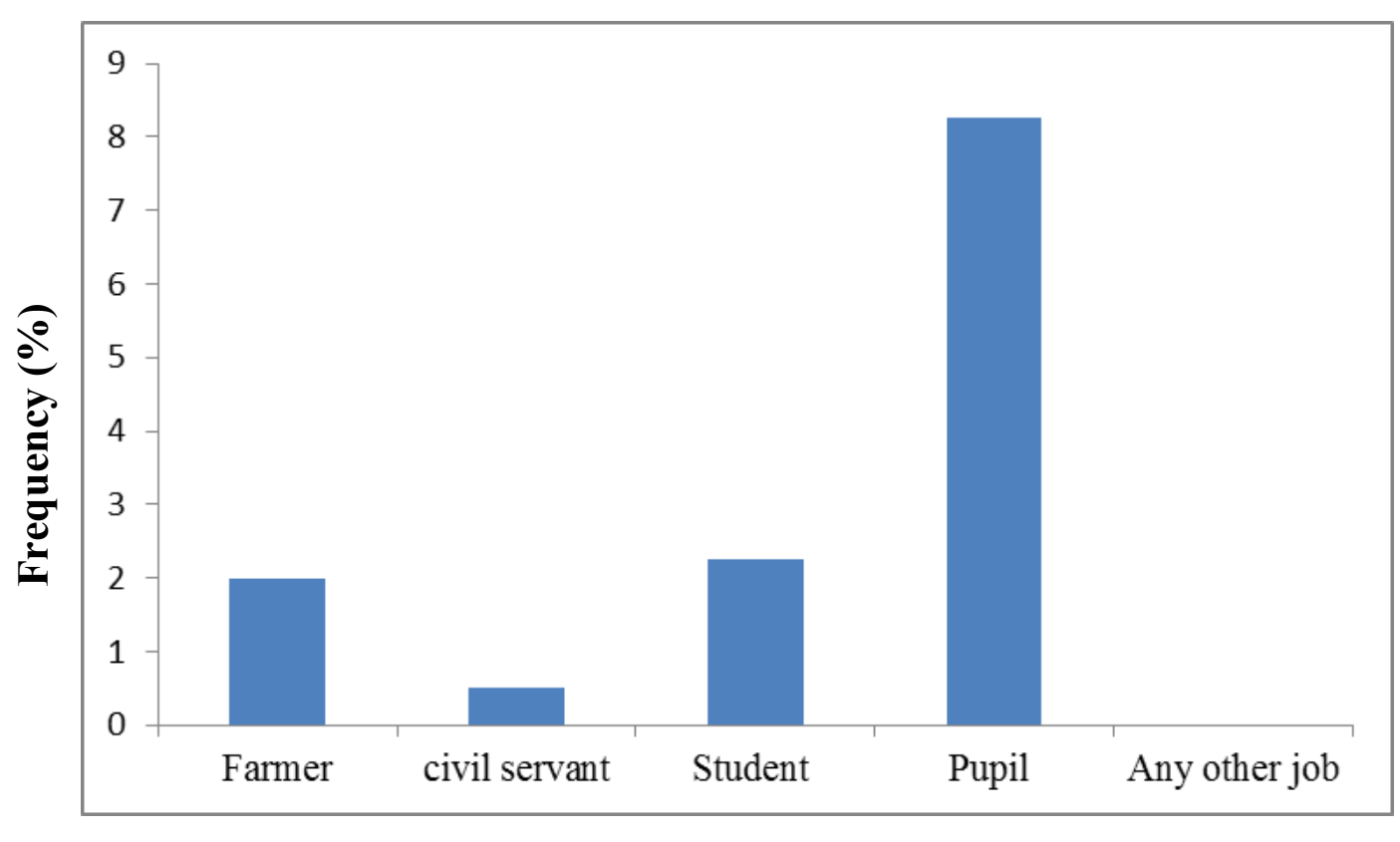

Occupation

Figure 6: Prevalence of STHs according to occupation.

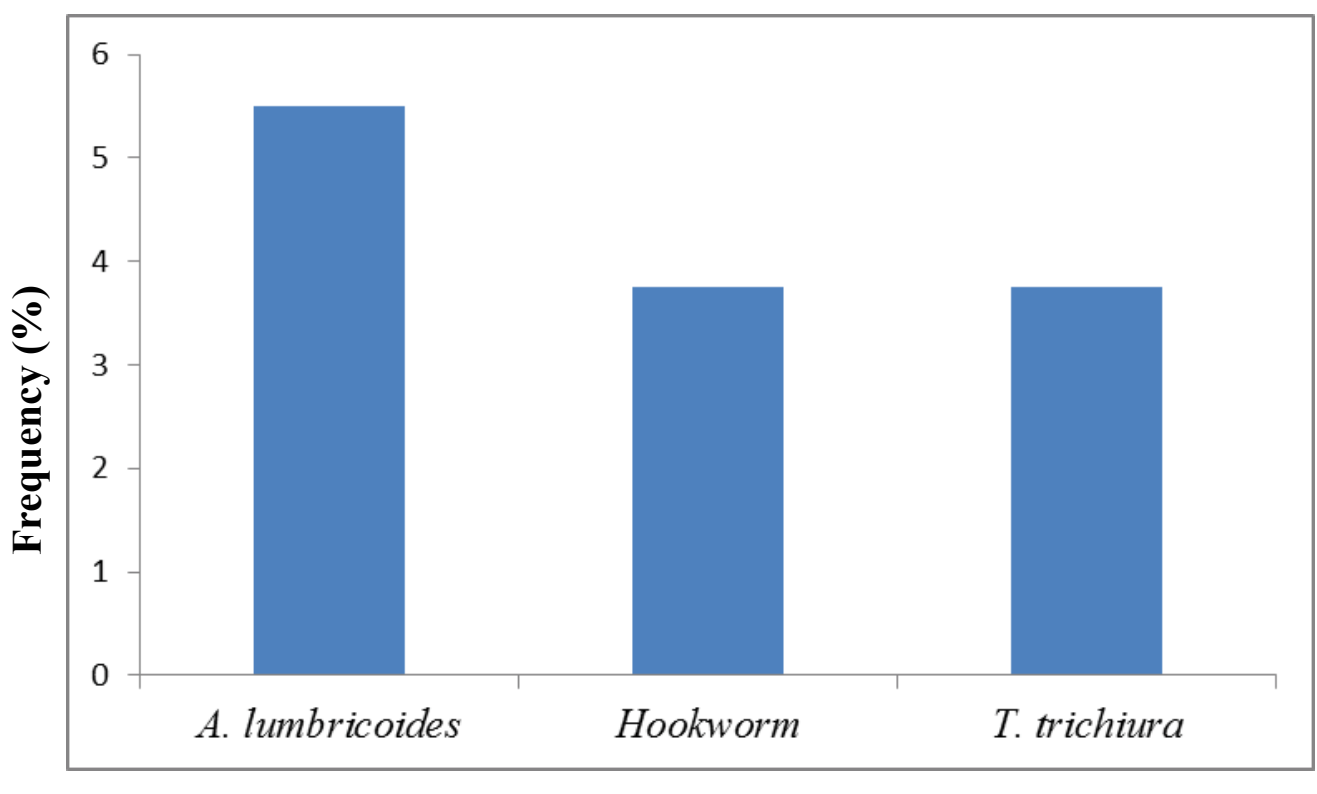

STHs in Nkambe

Figure 7: Prevalence of STHs in Nkambe. 


\section{Prevalence of different species of STHs infections according to demographic parameters.}

Three (3) species of STHs were observed in this study area (A. lumbricoides, Hookworm and T. trichuira) with different prevalence level. The prevalence (Figure 7) of A. lumbricoides was (5.5\%), higher than that of Hookworms and $T$. trichiura had the same prevalence of (3.75\%).

\section{Intensities of STHs infections}

Intensities of STHs infections are expressed by the level of parasitic load which is determined by counting the number of eggs of each parasites species in egg per gram (EPG). From this table it can be seen that out of the 400 stools sample examined, Hookworms showed the highest intensity of infection $(1000.00 \pm 228.03)$, followed by $A$. lumbricoides with $(671.43 \pm 317.27)$ while $T$. trichuira and showed the lowest level of intensity infection with $(478.57 \pm 237.68)$ as seen in Table 2 .

\section{Degree of infections with STHs}

Ascaris lumbricoides recorded the high number of heavy infections with a prevalence of $22.7 \%$ while no heavy infections were recorded for Hookworms and $T$. trichuira with prevalences of $15 \%$ respectively.

\section{Cure rate and fecal egg reduction rate}

Curing rate: Curing rate is known as the number of individuals' diagnosed positive with STHs infections but negative after two weeks of anthelminthic administration as it can be seen in Table 3 .

The anthelminthic drugs used in this study were a single dose of Albendazole $400 \mathrm{mg}$ and Mebendazole ( $500 \mathrm{mg}$ ) and their cure/reduction rates are as follows: A single dose of Albendazole (400 mg) was effective against $A$. lumbricoides. Eleven (11) individuals infected with A. lumbricoides took Albendazole and had a cure rate of $100 \%$. Whereas six (6) were given the same drug against Hookworms and had $66.6 \%$ as reduction rate; and lastly seven (7) individuals were given the same drug against Trichuris trichuira and only $1.8 \%$ reduction rate was realized. We can then conclude that a single dose of Albendazole was effective against $A$. lumbricoides but for Hookworm infection and Trichuris trichuira there was reduction of parasites eggs. A single dose of Mebendazole (500 mg) was quite effective against Hookworm. Nine (9) individuals who took Mebendazole against Hookworm had $100 \%$ cure rate, whereas $A$. lumbricoides twelve (12) individuals infected had $83.4 \%$ as reduction rate and lastly seven (7) individuals took the same drug and as reduction rate $1.8 \%$.

\section{Discussion}

This study investigated 400 individuals and 52 individuals were infected with at least one parasite. The overall prevalence was $13 \%$ similar to the study of Nganji NB, et al. [14], lower than that of the study carried out by Wabo $P$, et al. [15]. The prevalence of this study is higher than that of Sabi B, et al. [16]. The discrepancy in this prevalence could be due to the level of knowledge, attitude and practice towards sanitation among the population and also it maybe because of the geographical location plus the environmental conditions of the study area [17].

The prevalence of STHs infections was higher in males with $(7.25 \%)$ than the females with $(5.75 \%)$ as prevalence. The primary school children had high prevalence and this is contuary to that of Sabi B, et al. [16] in which those in the secondary school were the most infected. Those in the higher institution had no infection and this result correspond to that of Sabi B, et al. [16]. This could be due to the fact that children play a lot in dirty environment, defecate wherever they want

Table 2: Intensities of STHs infections among participants of Nkambe.

\begin{tabular}{|l|l|l|l|}
\hline & \multicolumn{2}{|l|}{ Number of participants } & EPG \\
\hline Parasite & Examined & Infected & Intensity (mean \pm SD) \\
\hline Ascaris lumbricoides & 400 & 22 & $671.43 \pm 317.27$ \\
\hline Hookworms & 400 & 15 & $1000.00 \pm 228.03$ \\
\hline Trichuris trichiura & 400 & 15 & $478.57 \pm 237.68$ \\
\hline
\end{tabular}

Table 3: Efficacy of Albendazole and Mebendazole against STHs before and after treatment.

\begin{tabular}{|c|c|c|c|c|c|c|}
\hline \multirow[b]{3}{*}{ Drugs } & \multirow[b]{3}{*}{ Parasites } & \multicolumn{4}{|c|}{ Number of participants } & \multirow[b]{3}{*}{ Cure rate } \\
\hline & & \multicolumn{2}{|c|}{ Before } & \multicolumn{2}{|l|}{ After } & \\
\hline & & Number & $\%$ & Number & $\%$ & \\
\hline \multirow{3}{*}{ ALB } & Ascaris lumbricoides & 11 & $2.75 \%$ & 0 & $0.0 \%$ & $100 \%$ \\
\hline & Hookworm & 6 & $1.5 \%$ & 2 & $0.5 \%$ & $66.67 \%$ \\
\hline & Trichuris trichuira & 7 & $1.8 \%$ & 3 & $0.8 \%$ & $57 \%$ \\
\hline \multirow{3}{*}{ MEB } & Ascaris lumbricoides & 12 & $3.0 \%$ & 2 & $0.5 \%$ & $83.4 \%$ \\
\hline & Hookworm & 9 & $2.3 \%$ & 0 & $0.0 \%$ & $100 \%$ \\
\hline & Trichuris trichuira & 7 & $1.8 \%$ & 7 & $1.8 \%$ & $0.0 \%$ \\
\hline
\end{tabular}


and are unable to practice hygiene because of their tender age [18]. According to Sunil P, et al. [19] reinfection is one of the major reasons for this high prevalence in school-aged children. The intensity of nematode infection was determined in terms of mean EPG. Hookworms had the highest mean intensity and it is higher than that of Sabi B, et al. [16] and [2] mean EPG. The intensity for $A$. lumbricoides and $T$. trichiura observed is lower than that of Nganji B, et al. [14].

A single dose of ALB $400 \mathrm{mg}$ was revealed to be effective against $A$. lumbricoides, Hookworms and $T$. trichuira though moderately with cure rate of $100 \%, 66.67 \%$ and $57 \%$ respectively. This Cure Rate of ALB against $A$. lumbricoides agrees with investigations of Megwi $L$ [20]. According to Sunil, et al. 2015 [19] a triple dose of ALB against $A$. lumbricoides showed $96 \%$ CR which is lower than the CR [21] indicated in this study. Hookworms had $66.67 \%$ as CR which was higher than the CR of Phonepasong $A$, et al. [22] who had CR of $36.0 \%$ for individuals that took ALB against Hookworms and this was surprising because the CR was unsatisfactory according to this study while a meta-analysis, randomized controlled trials of single dose Albendazole $400 \mathrm{mg}$ had an overall CR against Hookworms of $75 \%$ according to Keiser J, et al. [23] which is relatively higher than the $66.67 \%$ CR we have in this study. A single dose of ALB had moderate efficacy against $T$. trichuira with CR of $57 \%$ higher than that of Fikreslasie S, et al. [18] who had $42.3 \%$. Most studies have proven that a single dose of ALB against $T$. trichuira is unsatisfactory according to Keiser J, et al. and Olsen A, et al. [23,24]. A single dose of MEB $500 \mathrm{mg}$ had no effect against $T$. trichuira with $0.0 \%$ as CR. This finding disagreed to that Bruno L, et al. [25] who had $62.7 \%$ as CR. Keiser J, et al. [23] showed relatively poor efficacy of a single dose of MED $500 \mathrm{mg}$ against $T$. trichuira. The difference in these $C R$ for the two anthelminthic: ALB and MEB could be that, since MEB is poorly absorbed in the small intestine and its activity is limited only to adult worms mean while Albendazole is absorbed properly in the small intestine making it more effective when it is accompanied with fatty food, this drug then metabolized in the liver to give Sulphoxide compounds in which the distribution is high in the tissues [26].

The egg reduction rate (ERR) in this present study reveals that $A$. lumbricoides had $100 \%$ ERR, followed by Hookworms with $55 \%$ and lastly by $T$. trichuira with $44.2 \%$ for individuals treated with ALB. The ERR for $A$. lumbricoides in this study is similar to that of Dayan $A D$ [26]. A single dose of MEB $500 \mathrm{mg}$ revealed high ERR against Hookworms is $100 \%$ higher than that of Bruno L, et al. [25] with 70\% ERR. The ERR against $A$. lumbricoides revealed by Bruno L, et al. [25] is higher than that of this study with $62.9 \%$. The ERR for T. trichuira in this study is also lower than that of Ngo N, et al. [27]. This study disagrees with that of Nkengazong L, et al. [28] who had $7.2 \%$ ERR for $A$. lumbricoides and $20.8 \%$ for $T$. trichuira. These variability in ERR could be due to the intensity of infection and even co-infection with other helminths. Comparing the two drugs, it reveals that ALB was very much effective against $A$. lumbricoides because the intensity of infections was moderate for the both drugs [29].

\section{Conclusion}

The intestinal nematode, we found during this study were: A. lumbricoides, Hookworm and T. trichuira with an overall prevalence of $13 \%$. The most prevalent of these nematodes was $A$. lumbricoides with $5.5 \%$ as prevalence while Hookworm and $T$. trichuira had the same prevalence of $3.75 \%$. This study reveals that: $A$. lumbricoides infects most children between 2-10 years, a single dose of Albendazole $400 \mathrm{mg}$ showed high CR for A. lumbricoides and moderately for Hookworms and $T$. trichuira; Mebendazole showed high CR for Hookworms, moderately $A$. lumbricoides and unsatisfactory for $T$. trichuira. A single dose of ALB $500 \mathrm{mg}$ is recommended for the treatment of $A$. lumbricoides, Hookworms and T. trichuira while a single dose of MEB $500 \mathrm{mg}$ is also recommended for the treatment of Hookworm, and $A$. lumbricoides and not encouraged for the treatment of T. trichuira.

\section{Availability of Data and Materials}

Data and material are available to other researchers upon request.

\section{Competing Interest}

The authors declared that they have no competing interest.

\section{Funding}

No funding.

\section{Acknowledgements}

The author sincerely grateful to the laboratory Nkambe District Hospital and the entire population of Nkambe.

\section{Author's Contributions}

BRM, KPV, NACN and YC contributed to the design of the study, data collection, led the analysis and drafting of the manuscript. All authors read and approved the final manuscript.

\section{Ethical Approval and Consents to Participate}

Before starting the study properly, the research proposal was submitted to the Regional Hospital Review Board (RHB) in Bamenda with Registration N²1/APP/ $\mathrm{RDPH} / \mathrm{RHB}$ for evaluation and request for ethical clearance which was approved.

\section{References}

1. World Health Organization (2012) Eliminating soil transmitted helminthiases as a public health problem in children: Progress report 2001-2010 and strategic plan 2011-2020. 
2. Payne K, Lontuo F, Ngangnang G, Megwi L, Mbong E, et al. (2017) Prevalence and intensity of infection of Gastro-intestinal parasites in Babadjou, West Region of Cameroon. International Journal of Clinical and Experimental Medical Sciences 3: 14-22.

3. Kongs A, Marks G, Verle P, Van Der Stuyft P (2001) The unreliability of the kato-katz technique limits its usefulness for evaluating S. mansoni infections. Trop Med Int Health 6: 163-169.

4. Molyneux DH, Hotez PJ, Fenwick A (2005) "Rapid-impact interventions": How a policy of integrated control for Africa's neglected tropical diseases could benefit the poor. PLoS Med 2: e336.

5. Onwuliri CO, Anosike JC, Nkem CN, Payne VK (1993) The ecology of animal parasitic nematodes in endemic areas of Jos, Nigeria. Appl Parasitol 34: 131-137.

6. Bethony J, Brooker S, Albonico M, Geiger SM, Loukas A, et al. (2006) Soil-transmitted helminth infections: Ascariasis, trichuriasis, and hookworm. Lancet 367: 1521-1532.

7. Benedict M (2004) The influence of intestinal parasites on academic performance among primary school children in Nairobi province, Kenya. A thesis submitted in partial fulfillment of the degree of Public Health in the school of Health Science of Kenyatta University, 128.

8. Diakite A (2004) Les parasitoses digestives chez les patients hospitalise dans services de medicine de l'Hopital Nationale du Point G. These, Faculte de Medicine, de pharmacie et de d'Odontosstomatologie, Bamako-Mali, 180.

9. MINSANTE (2005) Programme Nationale de lutte contre Schistomiase et les helminth intestinale: Plan strategique 2005-2010. Ministre de la santé publique Cameroun.

10. World Health Organization (2002) Prevention and control of schistosomiasis and soil- transmitted helminthiasis: Report of a WHO expert committee. WHO Tech Report 2002, Ser 912: $1-57$

11. Tchuem A, Dongmo N, Ngassam $P$, Kenfack C, Feussom G, et al. (2013) Mapping of schistosomiasis and soil-transmitted helminthiasis in the regions of Littoral, North-West, South and South-West Cameroon and recommendations for treatment. BMC Infect Dis 13: 602.

12. Gellespie TR (2006) Non-invasive assessment of gastrointestinal parasite infections in free ranging primates. International Journal of Primatology 27: 1129-1143.

13. Thienpont D, Rochette FR, Vanperijs OFJ (1979) Diagnosis of verminosis by coprological examinations. Janssen Research Foundation, Beerse, Belgium, 48-67.

14. Nganji NB, Vincent KP, Yamssi C, Noumedem ACN (2011) Gastrointestinal helminth infections and associated risk factors amongst school aged children in Kouoptamo, Noun Division, West Region, Cameroon.

15. Wabo P, Mpoame M, Nkeng E, Bilong B (2012) Prevalence and intensity of infections of three neglected tropical diseases in patients consulted at a Traditional Health Care Centre in Dschang West- Cameroon. Trop Parasitol 2: 24-28.

16. Sabi B (2016) Gastrointestinal parasites amongst resident in Melong Moungo Division,Littoral Region, Cameroon.
Thesis submitted in partial fulfillment for the award of a Master degree in the university of Dschang, 41.

17. Girum T (2015) Prevalence of intestinal parasitic infections among patients with diarrhea at Wonago Health Center, Southern Ethiopia: A retrospective study. Immunology and Infectious Diseases 3: 1-6.

18. Fikreslasie S, Degarege A, Berhanu E (2014) Efficacy and side effects of albendazole currently in use against Ascaris, Trichuris and Hookworms among school children in Wondo Genet, Southern Ethiopia. Parasitol Int 63: 450-455.

19. Sunil P, Amrit L, Ravi B (2015) Intestinal parasitic infections among school children of Northern Kathmandu, Nepal. Asian Pacific Journal of Tropical Disease 5: S89-S92.

20. Megwi L (2013) Evaluation of the efficacy of albendazole, mebendazole and ivermectin goehelminths amongst school age children in Bafoussam. Thesis submitted in partial fulfillment for the award of a Master degree in University of Dschang, 86.

21. Amanda A, Anna O, Boualam K, Phouth I, John A, et al. (2017) Controlling Taeniasolium and soil-transmitted helminths in a Northern Lao PDR village: Impact of a triple dose albendazole regime. Acta Trop 174: 171-178.

22. Phonepasong $A$, Somphou $S$, Khampheng $P$, Vilavanh $X$, Jurg $U$, et al. (2012) Low efficacy of single albendazole and mebendazole against hookworm and effect on concomitant helminth infection in Lao PDR. Plos Negl Trop Dis 6: e1417.

23. Keiser J, Utzinger J (2008) Efficacy of current drugs against soil transmitted helminth infections: Systematic review and meta-analysis. JAMA 299: 1937-1948.

24. Olsen A, Namwanje H, Nejsum P, Roepstorffc A, Thamsborg SM (2009) Albendazole and mebendazole have low efficacy against Trichuris trichiura in school-age children in Kabale District, Uganda. Trans R Soc Trop Med Hyg 103: 443-446.

25. Bruno L, Antonio M, Marco A, Shaali M, Jerzy M, et al. (2014) Assessment of anthelmintic efficacy of mebendazole in school children in six countries where soil-transmitted helminths are endemic. PLoS Negl Trop Dis 8: e3204.

26. Dayan AD (2003) Albendazole, mebendazole and praziquantel. Review of non-clinical toxicity and pharmacokinetics. Acta Trop 86: 141-159.

27. Ngo N, Nkengazong L, Nkoa T, Adamou M, Ngue M, et al. (2017) Assessment of anthelmintic efficacy of mebendazole $500 \mathrm{mg}$ against soil- transmitted helminths in a high risk area of cameroon. International Journal of Tropical Disease and Health 25: 1-13.

28. Nkengazong L, Njiokou F, Wanji S, Teukeng F, Enyong $P$, et al. (2010) Prevalence of Soil- Transmitted Helminths and impact of albendazole on parasitic indices in Kotto Barombi and Marumba II villages (South West Cameroon). African Journal of Environmental Science and Technology 4: 115121.

29. Geary T, Woo K, Mccarthy J, MacKenzie C, Horton J, et al. (2010) Unresolved issues in anthelmintic pharmacology for helminthiases of humans. Int J Parasitol 40: 1-13. 